\title{
Analytic geometry method proved by finite difference on beam angular displacement
}

Wen-long Guo, Zhi-jiang Han, Zhi-hua Liu, Wang Lei, Xue-bing Guo, Zhao-lei, Yong-qiang Wang

(Shanxi Key Laboratory of Bridge Engineering Disaster Prevention and Mitigation, Key laboratory of Highway Construction \& Maintenance Technology in Loess Region, Shanxi Transportation Research Institute, Taiyuan, Shanxi,China,030006)

aE-mail: 392594485@qq.com

Key words: finite difference method; analytic geometry method; angular displacement; bending displacement

Abstract: Based on the analytical geometry method, small-plane bending deformation theory and approximate deflection curve equation, a simplified calculation method of section angular displacement will be proposed in this paper, which have been certified by the finite difference method. Then, the influence of number and space of measuring points on the experiment result had been detailed analyzed. Apparently, the method has good precision on premise of sufficient points, which could be an algorithms and experimental norm for beam angular displacement test on bridge loading test and damage identification.

\section{Introduction}

Generally, strain and displacement of the key cross-section are the dominating monitoring index in bridge structure analysis and experiment. Strain is more sensitive to the degree of damage of the current cross-section than the neighboring. Displacement is closely related to the stiffness of all structure sections within the whole affected line (plane) range. Damage of few sections have little difference to the displacement experiment results of key sections, which embarrassed bridge experiment, particularly, in old bridge. Strain calibration coefficient of some crack-sections is higher than norm while the displacement is lower. Therefore, making a reasonably assessment of damage of every experimental section and deducing the damage property of the concerned section, combined with mechanical analysis of the bridge structure, have become an issue to most bridge engineers ${ }^{[1]-[7]}$.

\section{Angular displacement calculation method based on analytic geometry}
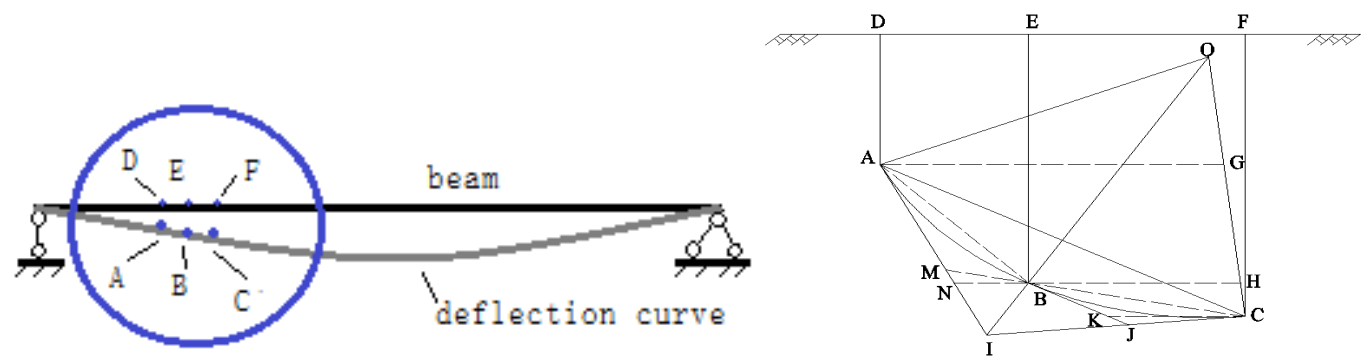

Fig.1 Deflection measurement point 
Analytic Geometry, generally, as one of the most simple and scientific methods to interpret natural phenomena is used widely. As show in fig. 1, a simplified beam bridge model deflected under load(force/moment), target unit DEF on the initial position while the centroid node $\mathrm{E}$. A, B, C on the corresponding deflection curve for the centroid $\mathrm{O}$ of $A B C$ with vertical displacement value $\mathrm{f}_{\mathrm{A}}, \mathrm{f}_{\mathrm{B}}, \mathrm{f}_{\mathrm{C}}$ respectively. Assuming that $\mathrm{AI} \mathrm{BJ} \mathrm{CI}$ tangent to deflection curve at $\mathrm{A}, \mathrm{B}, \mathrm{C}$ and $\mathrm{DF} / / \mathrm{AG} / / \mathrm{NH} / / \mathrm{CK}$.

Above all, we can derived that

$\mathrm{f}_{\mathrm{A}}$ is length of $\mathrm{DA}, \mathrm{f}_{\mathrm{B}}$ is length of $\mathrm{EB}, \mathrm{f}_{\mathrm{C}}$ is length of $\mathrm{FC}$.

$$
\text { So } \begin{aligned}
\angle \mathrm{GAB} \approx \frac{B E-A D}{L} & =\frac{f_{B}-f_{A}}{L} \\
\angle \mathrm{HBC} \approx \frac{C F-E B}{L} & =\frac{f_{C}-f_{B}}{L}
\end{aligned}
$$

Where $\mathrm{L}$ is length of $\mathrm{DE}$ and $\mathrm{EF}$.

And so

$$
\begin{aligned}
& \theta_{A}=\angle \mathrm{GAB}+\angle \mathrm{BAI}=\frac{f_{B}-f_{A}}{L}+\frac{\angle A O C}{4} \\
& \theta_{B}=\angle \mathrm{HBJ}=\angle \mathrm{HBC}+\angle \mathrm{CBJ}=\angle \mathrm{HBC}+\frac{\angle A O C}{4}=\frac{f_{C}-f_{B}}{L}+\frac{\angle A O C}{4}
\end{aligned}
$$

Where $\theta_{A}, \theta_{B}$ is the angular displacement at node $\mathrm{A}$ and $\mathrm{B}$ of unit $\mathrm{ABC}$.

And

$$
\because \angle \mathrm{HBC}=\angle \mathrm{MBN}=\angle \mathrm{ABN}-\angle \mathrm{ABM}
$$

$$
\because \mathrm{AG} / / \mathrm{NH}
$$

$$
\begin{aligned}
& \therefore \angle \mathrm{ABN}=\angle \mathrm{GAB}=\frac{f_{B}-f_{A}}{L} \\
& \because \angle \mathrm{ABM}=\angle \mathrm{BAC}+\angle \mathrm{BCA}
\end{aligned}
$$

And

$$
\begin{aligned}
& \because \angle \mathrm{BAC}=\angle \mathrm{BCA}=\frac{\angle A O C}{4} \\
& \therefore \angle \mathrm{ABM}=2 \times \frac{\angle A O C}{4}=\frac{\angle A O C}{2} \\
& \therefore \angle \mathrm{HBC}=\angle \mathrm{ABN}-\angle \mathrm{ABM}=\frac{f_{B}-f_{A}}{L}-\frac{\angle A O C}{2}
\end{aligned}
$$

From the Eq. (3) and (5), we have

$$
\theta_{B}=\angle \mathrm{HBC}+\angle \mathrm{CBJ}=\angle \mathrm{HBC}+\frac{\angle A O C}{4}=\frac{f_{B}-f_{A}}{L}-\frac{\angle A O C}{4}
$$

The average of the Eq. (3) and (6) can be obtained:

$$
\theta_{B}=\frac{1}{2}\left(\frac{f_{C}-f_{B}}{L}+\frac{\angle A O C}{4}+\frac{f_{B}-f_{A}}{L}-\frac{\angle A O C}{4}\right)=\frac{f_{C}-f_{A}}{2 L}
$$

In the same way: $\theta_{C}=\angle \mathrm{KCI}=\angle \mathrm{BCI}-\angle \mathrm{BCK}=\frac{\angle A O C}{4}-\frac{f_{C}-f_{B}}{L}$

Where $\theta_{C}$ is the angular displacement at node $\mathrm{C}$ of unit $\mathrm{ABC}$.

For the average deflect angle calculation, we can use Eq. $\theta_{A}$ and $\theta_{C}$ for both endpoints, and use Eq. $\theta_{B}$ for the points among both endpoints. Because of the direction of the geometric method can not be considered generally, so it deserves much more attention in the calculation. 


\section{Angular displacement proved by finite difference method}

The beam in the case of symmetrical bending deformation rear beam axis with a smooth curve in the plane, which is the deflection curve ${ }^{[8]-[14]}$. Assuming that the beam deflection curve equation for deformation can be described as: $y=f(x)$, apparently, the displacement value near by the measuring point $\mathrm{x}$ can be expressed as: $y=f(x+\Delta x)$. The equation can be deployed with Taylor series as

$$
\begin{gathered}
y=f(x+\Delta x)=f(x)+\Delta x \frac{d f}{x}+\frac{\Delta x^{2}}{2 !} \frac{d^{2} f}{x^{2}}+\frac{\Delta x^{3}}{3 !} \frac{d^{3} f}{x^{3}}+\cdots \\
\therefore \theta=\frac{d f}{x}=\frac{f(x+\Delta x)+f(x)}{\Delta x}+o(\Delta x), \text { where } o(\Delta x) \text { is a higher-order infinitesimal or }
\end{gathered}
$$

truncation error for $\theta$. When $o(\Delta x)$ is sufficiently small, the angular displacement of the section is:

$$
\begin{array}{ll}
\theta=\frac{d f}{x} \approx \frac{f(x+\Delta x)-f(x)}{\Delta x} & \text { First-order forward difference } \\
\theta=\frac{d f}{x} \approx \frac{f(x)-f(x-\Delta x)}{\Delta x} & \text { First-order backward difference } \\
\theta=\frac{d f}{x} \approx \frac{f(x+\Delta x)-f(x-\Delta x)}{2 \Delta x} & \text { First-order central difference }
\end{array}
$$

If the distance of point can be seen as increasing step length of point position, the finite difference equation can be achieved by analytic geometry:

$$
\theta_{B}=\frac{f_{C}-f_{A}}{2 L}=\frac{f(x+\Delta L)-f(x-\Delta L)}{2 \Delta L}=\frac{f(x+\Delta x)-f(x-\Delta x)}{2 \Delta x}
$$

Curvature of the cross-section is

$$
\frac{1}{\rho}=\frac{d^{2} f}{x^{2}} \approx \frac{f(x+\Delta x)-2 f(x)+f(x-\Delta x)}{\Delta x^{2}} \quad \text { Second-order difference }
$$

It can be obtained from equation (11) by using the finite difference method for solving unit center angle:

$$
\theta_{o}=\frac{\Delta x}{\rho}=\frac{d^{2} f}{x^{2}} \times \Delta x \approx \frac{f(x+\Delta x)-2 f(x)+f(x-\Delta x)}{\Delta x},
$$

Where in the Equation:

$f(x)$-The beam displacements were measured at the point $\mathrm{x}$, unit: $\mathrm{mm}$;

$f(x+\Delta x)$ - The beam displacement at the point which is $\Delta x$ far before the point $\mathrm{x}$, unit: $\mathrm{mm}$;

$f(x-\Delta x)$-The beam displacement at the point which is $\Delta x$ far after the point $\mathrm{x}$, unit: $\mathrm{mm}$;

$\Delta x$-The level distance bettween two adjacent measuring point, unit: $\mathrm{mm}$;

$\theta_{o}$ - unit center angle, unit: rad.

$$
\text { So } \angle \mathrm{AOC}=\frac{2 L}{\rho}=\frac{2(f(x+\Delta x)-2 f(x)+f(x-\Delta x))}{\Delta x}
$$


Where $\rho$ is the curvature radius of deflection curve of unit ABC.

So the angular displacement of unit $\mathrm{ABC}$ can be established by analytic geometry below

$$
\begin{gathered}
\theta_{A}=\frac{f_{B}-f_{A}}{L}+\frac{\angle A O C}{4}=\frac{f_{B}-f_{A}}{L}+\frac{f_{C}-2 f_{B}+f_{A}}{2 L} \\
\theta_{C}=\frac{f_{B}-f_{A}}{L}-\frac{\angle A O C}{4}=\frac{f_{B}-f_{A}}{L}-\frac{f_{C}-2 f_{B}+f_{A}}{2 L}
\end{gathered}
$$

\section{Example}

To verifying the influence and precision of the difference step-length on endpoint computation results, a pre-stressed concrete hollow-slab will exemplify the issue with concrete grade $\mathrm{C} 50$, elastic modulus $\mathrm{E}_{\mathrm{c}}=3.45 \times 10^{4} \mathrm{MPa}$, which span $\mathrm{L}=16 \mathrm{~m}$. In this paper, structure displacement value on dead load as the comparative index allowed for the dead load account for more than $60 \%$ in small and medium-span bridge. The division of units is 4,8 and 16 universally. Finally, exact, finite difference and analytic geometry solution of slab displacement will be deployed to analyze the error margin of precision for angular displacement in different divisions respectively. As showing in the figure 2, 3 and table1:

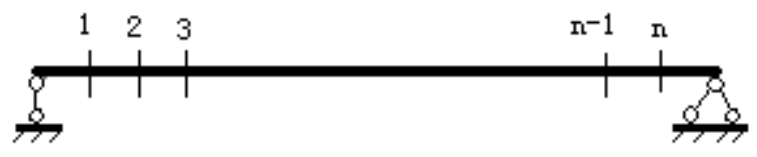

Fig.2 The division of displacement point

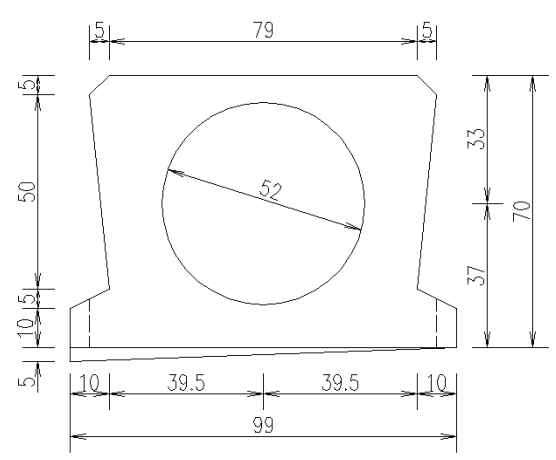

Fig.3 Hollow slab section

\section{Conclusion}

1. A simplified calculation method of bridge structural angular displacement have been presented and verified by finite difference method. The error-margin do meet the requirement of the accuracy of beam bridge loading experimental results.

2. The more measured point, the higher of the calculation accuracy of the beam angular displacement for each algorithm. As mentioned above, the maximum error margin is $19 \%$ when divided into 8 whereas $4 \%$ when 16 divisions.

3. Generally, analytic geometry and finite difference method applied universally in bridge structural field, but the former shared in both endpoints with a higher precision. 


\section{Acknowledgements}

This work was finally supported by the Transportation Construction Project(2013-1-06) sponsored by the Department of Transportation of Shanxi province, China.

\section{References}

[1] Zhou Ma-sheng. Li Yi-qian. Xiang Zhi-hai et al. A Modified Extended Bayesian Method for Parameter Estimation[J]. Journal of Tsinghua University(Natural Science). 2007. 12(5): $546-552$

[2] Cui Jun. He Shuan-hai. Song Yi-fan e et al. Research on evaluation of reinforced concrete board structure based on crack feature[J]. China Journal of Highway and Transport.2001, 14 (2): 58-60

[3] Cui Fei. Yuan Wan-cheng. Shi Jia-jun. Damage Detection of Structures Based on Static Response[J]. Journal of Tongji University(Natural Science) .2000.28（1） : 5-8.

[4] Zhang Qi-wei; Fan Li-chu. Damage Detection for Bridge Structures Based on Dynamic and Static Measurements [J]. Journal of Tongji University(Natural Science). 1998.26 (5) : 526-531

[5] Hajela P, Soeno F J. Recent developments in damage detection based on system identification methods [J].1990(2):1-10

[6] M.R.Banan, M.R Banan and K.D. Hjelmstad. Parameter estimation of structures from static response, I. Computational aspects [J]. Journal of Structural Engineering.1994,V120(11):3243-3258

[7] Liu xiao-yao, Liu hui. Damage detection of bridge[J]. Journal of Hefei university of technology(Natural Science).2001.24 (3) : 327-331.

[8] Xu Fan. A Method and Research for Bridge Deflection Measurement Base on Rotating Angle of Beam[D]. Chongqing Jiaotong University.2010;

[9] Yuan Ji-xiong, Wang Zhan, Zhou Bin. et al. Investigation of experimental methods used in measuring steel beam-to-column joint rotation[J]. Journal of Building Structures.2009;

[10] Han Jun jing, Cai yun, Wu Ling-ling, Chen Jing. Application of image processing based on DSP in the angle measurement[J]. Foreign Electronic Measurement Technology.

[11] Feng Kang. Numerical calculation method[M]. National Defence Industry Press. 1978: 465-606;

[12] Liu Qiong-tang. Mechanics of material[M]. China Machine Press. 2003： 126-140;

[13] Yang Fei. The Cause \& Analysis of the Displacement for Large Longitudinal Bridge Slab[J]. Shanxi science \& technology of communications. 2011,6 (213) : 69-71;

[14] Shao Xu-dong. Bridge construction [M]. China Communications Press. 004,Version1:68-100。 
Table1. Angular displacement calculation results and margin of error for different methods

\begin{tabular}{|c|c|c|c|c|c|c|c|c|c|c|c|c|c|c|c|c|c|c|}
\hline Number & $\begin{array}{l}\text { Calculation } \\
\text { solution }\end{array}$ & $\begin{array}{c}\text { Support } \\
\text { point }\end{array}$ & $\mathrm{L} / 16$ & $\mathrm{~L} / 8$ & $3 \mathrm{~L} / 16$ & $4 \mathrm{~L} / 16$ & $4 \mathrm{~L} / 16$ & $5 \mathrm{~L} / 16$ & $7 \mathrm{~L} / 16$ & $8 \mathrm{~L} / 16$ & $9 \mathrm{~L} / 16$ & $10 \mathrm{~L} / 16$ & $11 \mathrm{~L} / 16$ & $12 \mathrm{~L} / 16$ & $13 \mathrm{~L} / 16$ & $14 \mathrm{~L} / 16$ & $15 \mathrm{~L} / 16$ & $\begin{array}{l}\text { Support } \\
\text { point }\end{array}$ \\
\hline \multirow{6}{*}{$\begin{array}{l}4 \text { equal } \\
\text { portions }\end{array}$} & Displacement[mm] & 0.00 & & & & -7.99 & & & & -11.21 & & & & -7.99 & & & & 0.00 \\
\hline & $\begin{array}{l}\text { Exact Solution[rad } \\
\left./ 10^{3}\right]\end{array}$ & 2.222 & & & & 1.528 & & & & 0 & & & & -1.528 & & & & -2.222 \\
\hline & $\begin{array}{l}\text { Finite difference } \\
\text { solution[rad }\left[10^{3}\right]\end{array}$ & 1.998 & & & & 1.402 & & & & 0.000 & & & & -1.402 & & & & -1.998 \\
\hline & Error[\%] & -10.1 & & & & -8.3 & & & & 1 & & & & -8.3 & & & & -10.1 \\
\hline & $\begin{array}{l}\text { Analytic geometry } \\
\text { Solution }\left[\mathrm{rad} / 10^{3}\right]\end{array}$ & 1.848 & & & & 1.402 & & & & 0.000 & & & & -1.402 & & & & -1.848 \\
\hline & Error[\%] & -16.8 & & & & -8.3 & & & & 1 & & & & -8.3 & & & & -16.8 \\
\hline \multirow{6}{*}{$\begin{array}{l}8 \text { equal } \\
\text { portions }\end{array}$} & Displacement[mm] & 0.00 & & -4.36 & & -7.99 & & -10.38 & & -11.21 & & -10.38 & & -7.99 & & -4.36 & & 0.00 \\
\hline & $\begin{array}{l}\text { Exact Solution }[\mathrm{rad} \\
\left./ 10^{3}\right]\end{array}$ & 2.222 & & 2.031 & & 1.528 & & 0.816 & & 0 & & -0.816 & & -1.528 & & -2.031 & & -2.222 \\
\hline & $\begin{array}{l}\text { Finite difference } \\
\left.\text { solution[rad } / 10^{3}\right]\end{array}$ & 2.180 & & 1.998 & & 1.506 & & 0.805 & & 0 & & -0.805 & & -1.506 & & -1.998 & & -2.180 \\
\hline & Error[\%] & -19 & & -16 & & -15 & & -13 & & 1 & & -13 & & -15 & & -16 & & -19 \\
\hline & $\begin{array}{l}\text { Analytic geometry } \\
\text { Solution }\left[\mathrm{rad} / 10^{3}\right]\end{array}$ & 2.134 & & 1.998 & & 1.506 & & 0.805 & & 0.000 & & -0.805 & & -1.506 & & -1.998 & & -2.134 \\
\hline & Error $[\% 0]$ & -39 & & -16 & & -15 & & -13 & & 1 & & -13 & & -15 & & -16 & & -39 \\
\hline \multirow{6}{*}{$\begin{array}{l}16 \text { equal } \\
\text { portions }\end{array}$} & Displacement[mm] & 0 & -2.23 & -4.36 & -6.30 & -7.99 & -9.37 & -10.38 & -11.00 & -11.21 & -11.00 & -10.38 & -9.37 & -7.99 & -6.30 & -4.36 & -2.23 & 0.00 \\
\hline & $\begin{array}{l}\text { Exact Solution[rad } \\
\left./ 10^{3}\right]\end{array}$ & 2.222 & 2.172 & 2.031 & 1.812 & 1.528 & 1.191 & 0.816 & 0.414 & 0 & -0.414 & -0.816 & -1.191 & -1.528 & -1.812 & -2.031 & -2.172 & -2.222 \\
\hline & $\begin{array}{l}\text { Finite difference } \\
\text { solution }\left[\mathrm{rad} / 10^{3}\right]\end{array}$ & 2.229 & 2.180 & 2.038 & 1.817 & 1.532 & 1.195 & 0.818 & 0.416 & 0.000 & -0.415 & -0.818 & -1.195 & -1.532 & -1.817 & -2.038 & -2.180 & -2.229 \\
\hline & Error[\%] & 3 & 3 & 3 & 3 & 3 & 3 & 2 & 4 & 1 & 4 & 2 & 3 & 3 & 3 & 3 & 3 & 3 \\
\hline & $\begin{array}{l}\text { Analytic geometry } \\
\text { Solution }\left[\mathrm{rad} / 10^{3}\right]\end{array}$ & 2.218 & 2.180 & 2.038 & 1.817 & 1.532 & 1.195 & 0.818 & 0.416 & 0.000 & -0.415 & -0.818 & -1.195 & -1.532 & -1.817 & -2.038 & -2.180 & -2.218 \\
\hline & Error[\%o] & -2 & 3 & 3 & 3 & 3 & 3 & 2 & 4 & 1 & 4 & 2 & 3 & 3 & 3 & 3 & 3 & -2 \\
\hline
\end{tabular}

